\title{
EL QUIJOTE DE DOS CARAS - CERVANTES VERSUS AVELLANEDA
}

\section{INTRODUCCIÓN}

El Quijote es un texto que después de cuatro siglos de su aparición todavía no ha dejado de fascinarnos. La novela de Cervantes es el libro que ha seducido a todo lector, al viejo y al joven, al tonto y al listo, al loco y al cuerdo, al no educado y al erudita, al hombre común y al poeta, simplemente se trata del texto del que se ha enamorado la humanidad. «El arte debe ser como un espejo que nos revela nuestra propia cara», decía Borges; y el Quijote ha sido el espejo en el que cada lector a través de los siglos ha podido detectar el reflejo de su cara y de su época, o sea, ha podido verse con yelmo y cimera.

En 1605 se publicó en Madrid la Primera parte del Ingenioso hidalgo don Quijote de la Mancha, firmada por Miguel de Cervantes Saavedra. En 1614 se publicó en Tarragona el Segundo tomo del ingenioso hidalgo don Quijote de la Mancha, compuesto y firmado por Alonso Fernández de Avellaneda. En 1615 Miguel de Cervantes Saavedra, a su vez, publicó en Madrid la Segunda parte del ingenioso caballero don Quijote de la Mancha, especificando que él es el verdadero autor de su primera parte y denunciando la falsedad del nombre y del lugar de origen del autor del Quijote apócrifo. En el prólogo a la Segunda parte Cervantes escribe: «pues no osa parecer a campo abierto y al cielo claro, encubriendo su nombre, fingiendo su patria, como si hubiera hecho alguna traición de lesa majestad» (Cervantes, II, Prólogo: 675).

\section{IMITATIO}

Durante siglos, la obra de Cervantes ha inspirado un sinnúmero de continuaciones, parodias e imitaciones más o menos mediocres que han intentado prolongar las andanzas de sus personajes, desposeídos de ese quid divinum que les ha infundido su autor. Se escribieron novelas, obras de teatro, adaptaciones en verso, parodias inverosímiles, bufonadas de diverso tipo. Entre las obras tempranas pueden contarse dos sátiras de Alonso Jerónimo de Salas Barbadillo El caballero puntual (1614) y La estafeta del dios Momo (1627), donde un hidalgo pasa las noches leyendo los libros de caballerías; también frutos de una temprana inspiración cervantina son dos comedias del discípulo de Lope de Vega, Guillén de Castro: El curioso impertinente (1606), dramatización de los capítulos 33, 34 y 35 de la Primera parte del Quijote, y Don Quijote de la Mancha (1608); Francisco de Ávila es el autor del Entremés famoso de los invencibles hechos de Don Quijote de la Mancha.

\footnotetext{
* Dirección de la autora: Filozofska fakulteta, Oddelek za romanske jezike in književnosti, Aškerčeva 2, 1000 Ljubljana, Eslovenia. Correo electrónico: branka.ramsak@guest.arnes.si
} 
De todas las imitaciones y continuaciones del Quijote, la más interesante y la más enigmática sigue siendo la novela caballeresca de Alonso Fernández de Avellaneda que además encierra cierta mala fe porque su autor se esconde detrás del sinónimo jamás descodificado. Lo único que se puede afirmar con razonable seguridad sobre el autor del Quijote apócrifo es que era aragonés, católico, que conocía la Universidad de Alcalá de Henares, que era enemigo de Cervantes y ferviente admirador de Lope de Vega, y que se sentía ofendido por el autor del auténtico Quijote (cfr. Riquer, 1988; Riley, 2004).

Un año antes de la publicación de la Segunda parte del Quijote, en 1614, apareció en Tarragona en la imprenta de Felipe Roberto el texto Segundo tomo del Ingenioso Hidalgo don Quijote de la Mancha, que contiene su tercera salida y es la quinta parte de sus aventuras, compuesto por el Licenciado Alonso Fernández de Avellaneda, natural de la villa de Tordesillas.

En toda imitación hay cierto reconocimiento hacia el original. Durante el Renacimiento y el Barroco no era un fenómeno raro en la literatura española que unos escritores continuasen obras empezadas por otros autores: la primera novela pastoril en la lengua castellana Los siete libros de la Diana (1558 ó 1559) de Jorge de Montemayor es continuada por Gaspar Gil Polo con Diana enamorada (1564); existen varias continuaciones e imitaciones de la Celestina de Fernando de Rojas; la primera novela picaresca, Lazarillo de Tormes (1554), conoce dos continuaciones, una anónima ya en 1555, y otra escrita por Juan de Luna en 1620. El autor valenciano Juan Martí publicó la Segunda parte apócrifa (1602) de Guzmán de Alfarache (1599) de Mateo Alemán con el seudónimo Mateo Luján de Sayavedra. También en la literatura caballeresca frecuentemente los escritores componían continuaciones de novelas ajenas o de sus propias obras: por ejemplo, Garci Rodríguez de Montalvo revisó tres libros de Amadís de Gaula, escribió el cuarto y compuso la continuación del ciclo amadisiano con la novela Las sergas de Esplandián.

La concepción renacentista sobre la imitación era muy distinta a la actual, porque la imitatio en el sentido de la imitación de modelos clásicos constituía una de las bases de la enseñanza. Las escuelas latinas de retórica exigían de los futuros oradores que hiciesen ejercicios basados en la imitación de las obras de ciertos poetas y prosistas griegos y latinos. Los grandes humanistas del Renacimiento seguían esta pedagogía de la imitatio, pero no ciegamente sino como una forma de estímulo. Petrarca advierte:

Pretendo seguir la senda de los maestros, pero no siempre las huellas ajenas; quiero servirme de los escritos de otros no a hurtadillas, sino como quien pide permiso, y, si cabe, prefiero usar los míos; me complace el parecido, no la repetición, y aun ese parecido, no servil, donde luzca el ingenio en vez de la ceguera y la cortedad del admirador (Rico, 1993: 85).

\footnotetext{
${ }^{1}$ Se dice «la tercera salida» porque Cervantes anuncia la tercera salida de don Quijote al final del primer tomo; se dice también "la quinta parte" de las aventuras porque Cervantes dividió el primer tomo de su novela en cuatro partes.
} 
En la época de Cervantes la imitación se valoraba de modo positivo siempre cuando tuviera un carácter meliorativo y no se limitaba al simple plagio o a la repetición humilde de la obra imitada. Por eso muchos autores de la época intentaban superar sus modelos con continuaciones de las obras ya conocidas. En la reciente crítica se va descubriendo cada vez más que Cervantes también se servía de la imitación, no sólo en su inmortal novela, sobre todo en la Segunda parte, sino las influencias de Avellaneda se han ido observando también en algunas obras anteriores (cfr. Martín Jiménez, 2006: 373 , nota 4). ${ }^{2}$ Este hecho en ningún aspecto podrá disminuir la importancia del Quijote o la genialidad de su autor.

\section{EL QUIJOTE APÓCRIFO Y SU AUTOR MISTERIOSO}

Con la aparición de la obra de Avellaneda se ha abierto uno de los más grandes enigmas de la literatura clásica española: ¿quién es en realidad Alonso Fernández de Avellaneda? A pesar de todos los esfuerzos de la crítica e historia literarias que sobre todo a partir del siglo XIX intentaban revelar la verdadera identidad del autor apócrifo, el misterio todavía no se ha logrado desvelar enteramente ni se podrá hacerlo hasta que aparezca una prueba material (Riquer: 1988), un documento que descubra el verdadero rostro del autor apócrifo. En el siglo XVIII la crítica y la recién nacida historia literaria han empezado las investigaciones para tratar de determinar a la persona real que se esconde bajo el nombre Avellaneda. Desde el siglo XIX se ha ido componiendo una larga lista de posibles autores, atribuyendo la autoría a los autores famosos y a los menos famosos, entre otros a Juan Ruiz de Alarcón, a Guillén de Castro, a fray Luis de Granada, a Tirso de Molina, a Juan Martí, al conde de Lemos (Pedro Fernández de Castro), a varios autores del círculo de Lope de Vega o al mismo Lope de Vega, a Francisco de Quevedo o inclusive al mismo Cervantes. El número impresionante de posibles autores se debe al desconocimiento de un texto anterior a la publicación de la Primera parte del Quijote que aparentemente ha influenciado también a Cervantes: se trata del manuscrito de la autobiografía de Gerónimo de Passamonte, titulado Vida y trabajos de Gerónimo de Passamonte, compuesto en 1593. El manuscrito fue encontrado al principio del siglo XX en la Biblioteca Nazionale Vittorio Emanuelle III de Nápoles y publicado por primera vez

\footnotetext{
${ }^{2}$ El Quijote apócrifo circuló en forma manuscrita con anterioridad a su publicación, de modo que Cervantes conoció el manuscrito de Avellaneda antes de empezar a escribir la Segunda parte del Quijote. Lo conocía antes de escribir el entremés La guarda cuidadosa (que lleva la fecha 6 de mayo de 1611; un soldado que envía un memorial al rey, al cual se le otorga un misérrimo valor), o la novela ejemplar El coloquio de los perros (las Novelas ejemplares llevan la fecha de la solicitud de aprobación 2 de julio de 1612; Cervantes alude varias veces a los episodios del Quijote apócrifo y se burla de los comentarios teológicos de la Vida de Passamonte), o la parte versificada del Viaje del Parnaso (compuesta hacia 1612 y concluida antes de julio de 1613; en el capítulo VIII Cervantes alude a Passamonte como autor del Quijote apócrifo a través del personaje de Promontorio, soldado napolitano). En las obras mencionadas Cervantes realiza continuas alusiones al Quijote apócrifo y reproduce literalmente ciertas expresiones de Avellaneda. De modo que el manuscrito de Avellaneda llegó a sus manos seguramente antes del mes de mayo de 1611 (cfr. Martín Jiménez, 2006: 372).
} 
en 1922 por Raymond Foulché-Delbosc en la Revue Hispanique. Más tarde fue reeditado con grafía modernizada en 1956 por José María de Cossío. Sus primeros editores todavía no sospechaban que el autor apócrifo, Alonso Fernández de Avellaneda, pudiera ser Gerónimo de Passamonte (cfr. Martín Jiménez, 2001: 101; Riquer, 2003: 442-450).

La primera contribución significante a la desmitificación de la figura del autor apócrifo la ha hecho Martín de Riquer en 1969 en su artículo «El Quijote y los libros» en los Papeles de Son Armadans (XIV, págs. 9-24) y en 1972, en la Introducción a su edición del Quijote apócrifo. Riquer propuso que Avellaneda podía ser el compañero militar de Cervantes, soldado aragonés Gerónimo de Passamonte, autor de la autobiografía Vida y trabajos de Gerónimo de Passamonte. En 1984, Daniel Eisenberg desarrolló la propuesta de Riquer en eun artículo titulado «Cervantes, Lope and Avellaneda». Riquer ampliamente estudió y minuciosamente presentó su hipótesis en el estudio Cervantes, Passamonte y Avellaneda en 1988, y posteriormente la revisó en el texto Para leer a Cervantes en 2003. Para sustentar su hipótesis, Riquer compara el manuscrito de Passamonte con el texto de Avellaneda $y$ encuentra entres ellos varias coincidencias.

\section{CERVANTES Y PASSAMONTE: SU DISPUTA PERSONAL Y LITERARIA}

Passamonte en su juventud había conocido a Cervantes en varias campañas militares como la batalla de Lepanto (1571), la jornada de Navarino (1572) y la conquista de Túnez (1573). Gerónimo de Passamonte también sufrió un largo cautiverio ${ }^{5}$, mucho más largo que el de Cervantes. Dieciocho años fue prisionero de los turcos; una temporada de la cautividad la pasó remando en las galeras turcas. Cuando regresó a España, compuso el manuscrito de carácter autobiográfico en el que narraba su infancia y su juventud, los episodios militares y las penalidades de su cautiverio. En esa autobiografía se puede leer que el aragonés ha hecho suyo el comportamiento heroico en Lepanto que en realidad correspondió a Cervantes. Como es bien sabido, Cervantes estaba con fiebre cuando participó en la batalla oponiéndose al consejo de su capitán de quedarse con los demás enfermos. En el texto de Passamonte, en una escena que describe la toma de la Goleta en 1573, en la que no había auténtica batalla debido a la huida del enemigo, Passamonte se

\footnotetext{
${ }^{3}$ Es interesante la observación de Rafael Salillas que en una conferencia, pronunciada en 1905, decía: «Tal vez no sea Ginés de Pasamonte un personaje en absoluto inventado. El rasgo descriptivo que lo singulariza parece indicador de un conocimiento personal» (cfr. Riquer, 2003: 457); y en 1950, en un artículo de sólo tres páginas con el título Pasamonte, publicado en Romanische Forschungen (LXII, págs. 365-367), Alois Achleitner señaló la relación entre Ginés de Passamonte, personaje de la ficción, y Gerónimo de Passamonte, personaje real, autor de la autobiografía y compañero militar de Cervantes. Otros autores que han hecho observaciones interesantes sobre Gerónimo de Passamonte son Olga Kattan en 1970, Randolph D. Pope en 1974 y Margarita Levisi en 1984 (cfr. Riquer, 2003: 442-450).

${ }^{4}$ Martín de Riquer prefiere la grafía Passamonte a la de Pasamonte, y Gerónimo a Jerónimo, porque conserva la grafía de la autobiografía: Gerónimo de Passamonte (1553 - 16??).

${ }^{5} \mathrm{Al}$ defender la Goleta en Túnez fue apresado por los turcos en 1574.
} 
presentaba a sí mismo como un enfermo con calentura que, a pesar del consejo de su capitán que no participara en la batalla, se empeñaba en pelear.

\subsection{Capítulo XXII de la Primera parte del Quijote}

Al conocer la existencia del manuscrito de Gerónimo de Passamonte, su antiguo compañero de milicia, y al comprobar que Passamonte trataba de usurparle su comportamiento heroico de Lepanto, Cervantes lo satirizó en la Primera parte del Quijote como el personaje narrativo Ginés de Pasamonte en el episodio de los galeotes, uno de los episodios más famosos de la Primera parte (capítulo XXII). «Ginés me llamo y ... Pasamonte es mi alcurnia» (I, 22: 264) es el jefe de los delicuentes liberados por don Quijote. La concordancia absoluta en nombre y apellido entre el personaje narrativo Ginés de Pasamonte y el soldado real Gerónimo de Passamonte no puede ser casual. Cervantes presenta al galeote también como autor del libro La vida de Ginés de Pasamonte aludiendo claramente a la autobiografía de Gerónimo de Passamonte Vida y trabajos de Gerónimo de Passamonte.

Cervantes denigró en su novela a Gerónimo de Passamonte convirtiendo al digno galeote cristiano, que había remado como forzado en galeras turcas, al galeote condenado por sus delitos a las galeras reales de España. Dice Sancho: «Ésta es cadena de galeotes, gente forzada del rey, que va a las galeras» (Cervantes, I, 22: 258). El odio entre Cervantes y Passamonte, entonces, provenía de los años que compartieron como compañeros militares. El conflicto surge también en la novela entre don Quijote y Ginés que se insultan: antes de recibir la lluvia de piedras por parte de los galeotes, don Quijote le insulta a Ginés porque éste se niega a ir al Toboso, diciendo: «don hijo de la puta, don Ginesillo de Paropillo, o como os llamáis, que habés de ir vos solo, rabo entre piernas, con toda la cadena a cuestas» (Cervantes, I, 22: 270).

En la primera edición del Quijote de 1605 se han suprimido, por descuido del impresor, dos breves episodios que aparecen en la segunda edición de Juan de la Cuesta: el primero se añade al capítulo XXIII y se refiere al robo del asno de Sancho y otro se añade al capítulo XXX en el que Sancho recupera a su rucio. E1 robo se 1o atribuye a Ginés de Pasamonte que Cervantes lo insulta otra vez sin piedad: "Ginés del Pasamonte, el famoso embustero y ladrón» (Cervantes, Apéndice: 1347), y «¡Ah, ladrón Ginesillo! ¡Deja mi prenda, suelta mi vida, no te empaches con mi descanso, deja mi asno, deja mi regalo! ¡Huye, puto: auséntate, ladrón, y desampara lo que no es tuyo!» (Cervantes, Apéndice: 1349).

Cervantes ha retratado de modo ofensivo al soldado Ginés de Pasamonte porque sentía que el verdadero Gerónimo de Passamonte se había comportado con él deshonestamente. Las mentiras sobre las falsas hazañas heroicas de Passamonte que podían leerse en el manuscrito de la Vida circularon entre los lectores a partir de su composición en 1593. Por eso, Cervantes, que sin duda le había ayudado a Passamonte en su época militar, se sintió ofendido y de ahí una crítica tan violenta en la Primera parte del Quijote. 


\subsection{La Novela del Capitán cautivo}

Además de responderle a Passamonte a sus ofensas militares con ridiculización de su persona a través de la denigración del galeote Ginés, Cervantes quiso demostrar también su superioridad literaria. Por eso decidió realizar una imitación meliorativa de la autobiografía de Passamonte y compuso su propia autobiografía con el título la Novela del Capitán cautivo que la insertó en la Primera parte del Quijote en los capítulos XXXVII y XLII. Cervantes no había plagiado literalmente a Passamonte, sino había querido mejorar sus episodios militares, dándole a entender a su rival su superioridad literaria.

Cervantes se sirve en su relato de sus propias experiencias militares y las del cautiverio en Argel. La narración del Capitán cautivo, al contrario de otros episodios que son de carácter ficcional, presenta hechos reales. Tanto la autobiografía de Passamonte como el Capitán cautivo se desarrollan en torno a tres motivos temáticos, basados en los hechos históricos: las batallas entre turcos y cristianos entre los años 1571 y 1574 (años que Cervantes y Passamonte compartieron en el ejército), la vida del cautiverio y los peligros de la vuelta a las tierras cristianas, tras haber obtenido la liberación del cautiverio. Los dos relatos concuerdan en muchos detalles, lo que minuciosamente presenta Alfonso Martín Jiménez en sus estudios $(2001,2005)$.

Si no por otra cosa, ya por las relaciones intertextuales podemos afirmar con toda seguridad que Cervantes había conocido perfectamente la identidad de su rival. Al haber comparado los dos textos, nos damos cuenta que Cervantes imitó a Passamonte aunque mejorando el texto de su rival militar y literario. Y aunque se ha creído siempre que Avellaneda había sido el imitador de Cervantes, ahora se ha descubierto que Cervantes fue el primer imitador que de modo meliorativo y dentro del concepto de la imitatio renacentista había imitado a Avellaneda, si es que aceptamos la hipótesis de que su verdadera identidad se esconde detrás de la persona de Gerónimo de Passamonte.

\subsection{El Quijote apócrifo}

Cuando Gerónimo de Passamonte leyó la Primera parte del Quijote descubrió que su personalidad aparecía ridiculizada en el personaje cervantino de Ginés de Pasamonte y que Cervantes se había servido del manuscrito de su autobiografía para componer el relato sobre el Capitán cautivo. Para no identificarse con el galeote de la novela cervantina en su propia novela tuvo que esconder su identidad. Passamonte tuvo una justificación muy fuerte para la composición del Quijote apócrifo - él quiso contestar a la novela de Cervantes mediante la continuación imitativa porque éste previamente se había servido de los episodios de su autobiografía. En el prólogo Avellaneda explica algunos motivos por los cuales prosiguió con las aventuras de don Quijote y Sancho. En realidad, afirma que Cervantes había leído su manuscrito y que se había servido de él para componer la Novela del Capitán Cautivo: 
No le parecerán a él lo son las razones desta historia, que se prosigue con la autoridad que él la comenzó y con la copia de fieles relaciones que en su mano llegaron; y digo mano, pues confiesa de sí que tiene una sola; y hablando tanto de todos, hemos de decir dél que, como soldado tan viejo en años cuanto mozo en bríos, tiene más lengua que manos. (Avellaneda, Prólogo: 195-196).

Sin embargo, Avellaneda, aunque ofendido por Cervantes, por su parte él no quiere ser ofensivo como Cervantes ha sido hacia él, "huyendo de ofender a nadie ni de hacer ostentación de sinónimos voluntarios» (Avellaneda, Prólogo: 197), refiriéndose posiblemente a los nombres con los que Cervantes había calificado al galeote: Ginés o Ginesillo de Pasamonte o de Parapilla o de Paropillo. Avellaneda se siente íntegramente autorizado para continuar la historia de la Primera parte del Quijote, cuyo autor le había ofendido e imitado.

Como apoyo a la hipótesis que Alonso Fernández de Avellaneda es en realidad Gerónimo de Passamonte puede servir también el hecho de que existen varias coincidencias expresivas y temáticas entre la Vida y trabajos de Gerónimo de Passamonte y el Quijote apócrifo.

El Quijote de Avellaneda es un libro escrito con mucha rapidez, con errores y sin revisiones. Las fuentes que las utiliza Avellaneda vienen de Cervantes, de Lope de Vega, del romancero, de la novela picaresca y de la literatura italiana. Las faltas estilísticas o los errores sintácticos que aparecen en el texto son frutos de un autor descuidado con poca experiencia literaria, que fue urgido más por el tiempo que por el deseo de publicar una obra perfecta (Marín, 1988: 288). También la impresión del libro fue rápida y descuidada, mientras que la venta se limitó sólo al arzobispado de Tarragona donde se hizo conocer por sus círculos literarios.

Cervantes mismo ha dado una propuesta literaria a todos sus posibles continuadores terminando el primer tomo del Quijote con la anuncia de una tercera salida con destino a Zaragoza. Cervantes además acabó su primer libro de un modo burlesco - con el verso de Ariosto que procede del Orlando furioso con el que invita a otros escritores que continúen su obra: «Forse altro canterà con miglior plectro» (Cervantes, I, 52: 653). ${ }^{6}$ Como aragonés, Passamonte conocía perfectamente los lugares por los cuales don Quijote debería viajar en su tercera salida. También conocía perfectamente el italiano y a Ariosto que lo había leído en su propio idioma.

En la obra de Avellaneda se narran nuevas aventuras de don Quijote y Sancho cuando a su aldea que ahora ya no es «un lugar de la Mancha, de cuyo nombre no quiero acordarme» (Cervantes, I, 1: 37), sino ya desde el primer capítulo se sabe que se trata de Argamasilla en la Mancha, llegan unos caballeros de Granada.

\footnotetext{
${ }^{6}$ La traducción sería: "Quizá otro cantará con mejor plectro". Lope de Vega acude al mismo verso en el prólogo de su obra poética La hermosura de Angélica en 1602.

${ }^{7}$ Lo que demuestra en su autobiografía.

${ }^{8}$ No se sabe si se trata de Argamasilla de Alba (cercana al Toboso) o de Argamasilla de Calatrava. Cervantes mismo menciona al final de la Primera parte del Quijote el pueblo Argamasilla como "lugar de la Mancha". Se trata de la simetría con la famosa primera frase de su novela.
} 
Ellos están en el camino a Zaragoza porque quieren participar en unas justas. Uno de ellos, llamado don Álvaro Tarfe, se aloja en la casa de don Quijote. Durante la conversación amistosa, don Álvaro se da cuenta de la locura de don Quijote. Éste decide volver a sus rutas caballerescas junto con su escudero Sancho Panza y dirigirse él también a las justas zaragozanas. El nuevo nombre de don Quijote es el Caballero Desamorado porque el caballero andante ha renunciado al amor de Dulcinea. Cuando llega a Zaragoza, primero lo meten en la cárcel, luego participa en las justas y gana el premio. Camino de vuelta don Quijote y Sancho conocen a una mujer con el nombre de Bárbara, a quien don Quijote llama la reina de Zenobia. Siguen varias aventuras en Alcalá de Henares y Madrid. Al final Sancho se queda en Madrid sirvinedo a un marqués; y don Álvaro Tarfe encierra a don Quijote en un manicomio de Toledo porque a lo largo de las aventuras don Quijote apócrifo, igual que el auténtico, padece de constantes desdoblamientos de la personalidad.

Avellaneda siguió en líneas generales al planteamineto narrativo original. Hay muchas semejanzas entre los dos textos, también narrativas, pero hay también muchas diversidades y oposiciones. Entre las básicas que definen la esencia de las dos obras es también el concepto de locura - Cervantes había enfocado la locura desde la perspectiva literaria, presentando los libros de caballería como un contrapunto de la realidad y un modelo literario. Mientras que para Avellaneda la locura es el agente mental, moral y social del protagonista que encierra en sí el peligro. Éste puede curarse con la vida misericordiosa y la lectura de los libros devotos (Avellaneda, VII: 309).

\subsubsection{Referencias textuales}

En el prólogo de Avellaneda hay cuatro referencias textuales a Cervantes. Siguen los primeros dos capítulos que tienen el número mas grande de las referencias textuales: en el primer capítulo existen 13 elementos de intertextualidad a la novela de Cervantes, en el segundo 21. A partir del tercer capítulo el número de los ejemplos de intertextualidad se mantiene más moderado. Sólo en los capítulos IX y XI no aparece ninguna referencia textual a Cervantes. El breve capítulo IX narra la liberación de don Quijote de la cárcel en Zaragoza. Le salva el caballero granadino don Álvaro Tarfe, personaje independiente y producto original de invención de Avellaneda. El capítulo XI describe cómo los caballeros jugaron la sortija en la calle del Coso en Zaragoza. Entre los capítulos XV y XX, donde Avellaneda insertó dos cuentos - El rico desesperado y Los felices amantes -, sólo hay dos fragmentos intertextuales que remiten a Cervantes. Esa independencia se debe probablemente al hecho de que los cuentos fueron compuestos antes del resto de la novela. Además Avellaneda utilizó el mismo procedimiento narrativo - inserción de breves novelas independientes en la narración principal - que Cervantes en su Primera parte, por ejemplo con El curioso impertinente. Mientras que la introducción a la novela insertada en Cervantes significa un avance en las técnicas narrativas, en Avellaneda

\footnotetext{
${ }^{9}$ En la Segunda parte Cervantes ya no utiliza esa técnica narrativa.
} 
el mismo procedimiento narrativo no tiene otra función que la de enlazar dos textos. En el resto de la novela Avellaneda acude con cierta regularidad al texto de Cervantes de 1605 y se refiere a él entre 3 y 5 veces en cada capítulo. La novela termina con el capítulo XXXVI.

Con el avance de la narración Avellaneda va ganando su progresiva independencia frente a la novela de Cervantes porque la mayoría de las referencias a la Primera parte del Quijote se encuentra acumulada en los primeros capítulos.

Si cabe determinar qué episodios de la obra de Cervantes son más aludidos, nos damos cuenta que la mayor parte de las referencias textuales se centran en la primera mitad del Quijote - hasta 81 elementos proceden de los capítulos I al XXVI (Gómez Canseco, 2000: 64). De modo que podemos concluir que a Avellaneda le interesaron sobre todo los episodios cómicos de Cervantes y mucho menos sus reflexiones sobre los conceptos ideológicos o literarios.

\subsubsection{Los modos de narrar y el género}

Avellaneda seguramente jamás reflexionó sobre los objetivos literarios de su obra si la juzgamos por errores en la composición, descuidos en la trama o poca habilidad estilística. Su obra es más bien reacción espontánea a una ofensa real. Avellaneda no afrontó en ningún momento de su texto los precedimientos metaficcionales que Cervantes los había anunciado en la Primera parte y las desarrolló tan magistralmente en la Segunda parte del Quijote.

Avellaneda explica en su prólogo que entiende el término novela en su sentido italiano de narración breve (novella), igual que hiciera Cervantes con Novelas ejemplares. Como gran admirador de Lope de Vega, Avellaneda se adhiere plenamente a la propuesta lopesca de identificación entre comedia y novela. Por eso, llama a su libro «comedia» en la que introduce varios elementos teatrales: «No sólo he tomado por medio entremesar la presente comedia con las simplicidades de Sancho Panza...» (Avellaneda, Prólogo: 197). En esta cita se mencionan tres elementos dramáticos: la calificación de la obra como comedia en la que acude al entremés y donde Sancho Panza es un personaje gracioso que divierte a sus lectores.

\subsubsection{La estructura interna}

E1 Quijote apócrifo contiene una simetría perfecta de una comedia lopesca. La novela tiene tres partes - la quinta, la sexta y la séptima parte que representan continuaciones de las cuatro partes (dos salidas) del Ingenioso hidalgo de Cervantes. Cada parte se divide en doce capítulos que son perfectamente equilibrados y organizados según la acción, el protagonismo de personajes y el recorrido geográfico. En realidad, como si se tratase de las tres jornadas de una comedia en la que la acción se plantea, se complica y se resuelve.

\footnotetext{
${ }^{10}$ Por ejemplo en la Desdicha por la honra considera que las novelas tienen los mismos preceptos que las comedias. También presenta su obra La Dorotea como "acción en prosa".
} 
En cuanto al espacio, don Quijote de Avellaneda apenas recorre el campo. El espacio de la narración es sobre todo urbano porque don Quijote viaja muy rápido de una ciudad a otra. La narración se expande en las siguientes ciudades: Ateca, Zaragoza, Sigüenza, Alcalá de Henares, Madrid, Toledo.

La distribución perfecta de las partes tiene su reflejo también en el protagonismo de los personajes secundarios. A menudo los héroes no evolucionan, se parecen entre sí como figuras con caracteres parecidos.

En cuanto al tiempo, Avellaneda dice que la acción se inicia seis meses después del final del Quijote de Cervantes. Pero luego el autor se olvida del tiempo y frecuentemente convierte la narración en una sucesión de episodios sin conexión interna. La trama tiene extensas digresiones dando impresión de escasa organización interna.

El cierre de la novela anuncia dos continuaciones: la historia de Sancho Panza y su mujer y otra, una nueva salida de don Quijote. Al final Avellaneda imita literalmente a Cervantes concluyendo su narración también con el verso de Ariosto, sólo que esta vez en español: «no faltará mejor pluma que los celebre» (Avellaneda, XXXVI: 721). De este modo Avellaneda deja la estructura del relato completamente abierta permitiendo la posibilidad de otras continuaciones, aunque don Quijote enloquecido se encuentra en Toledo encerrado en el manicomio llamado la Casa del Nuncio.

\subsubsection{Las voces narrativas}

Parecida a la voz narrativa del autor árabe Cide Hamete Benengeli, invención genial de Cervantes, el autor apócrifo inventó la voz de Alisolán que pretende ser su imagen aunque muy lejos de la ironía con la que Cervantes había caracterizado el papel de su historiador árabe. Alisolán es sabio, morisco y aragonés que entre unos documentos históricos encuentra el manuscrito arábigo en el que se narra la tercera salida de don Quijote. Como verdadero historiador de las aventuras de don Quijote aparece el sabio Alquife, personaje procedente de Amadís de Gaula. Existe otra voz narrativa en tercera persona - la del traductor y transcriptor de la historia que el único maneja todos los hilos entre el original árabe y el texto que leemos.

Alonso Fernández de Avellaneda fue, por lo visto, un gran admirador del Quijote de Cervantes. Según las palabras de Martín de Riquer «lo continuó y lo imitó con entusiasmo, celebrando muy de veras episodios y pasajes que se narran en la Primera parte, aunque es cierto también que profesaba un auténtico odio hacia Cervantes» (Martín Jiménez, 2001: 160). Entre distintas respuestas a Cervantes, tanto exteriores como narrativas, Avellaneda no superó en ningún aspecto a su modelo. E. C. Riley (2004: 111) considera que: «El libro es en ocasiones bastante divertido, tiene una especie de unidad que agradó al siglo XVIII y muestra una cierta fluidez narrativa que recuerda a algunos de los novelistas de la literatura picaresca».

\section{LA SEGUNDA PARTE DEL QUIJOTE DE CERVANTES}

La disputa literaria entre Passamonte y Cervantes no se para ahí. Cervantes en 1615 publica la Segunda parte del ingenioso caballero don Quijote de la Mancha, que es, 
entre otras cosas, también una refinada réplica al Quijote apócrifo en la que Cervantes ensaya varias estrategias narrativas. Lo que sí tenemos que agradecerle a Avellaneda es que con su texto apócrifo había provocado aun más la genialidad de Cervantes que culminó creando episodios satíricos, burlescos, correctores. Eso prueba que Cervantes había leído el texto de Passamonte con mucha atención y que lo conoció detalladamente antes de terminar la redacción del segundo tomo. Los estudios más recientes del Quijote de 1615 se inclinan hacia la gran probabilidad de que Cervantes conocía el manuscrito del Quijote de Avellaneda (cfr. Gilman, 1951) desde el primer momento. Su influencia es evidente en todos los capítulos de la segunda parte del Quijote cervantino, desde el primero hasta el último, y no sólo en algunos episodios esporádicos.

Toda la Segunda parte del Quijote de Cervantes está encubierta de referencias al Quijote apócrifo, dando a entender que él es mejor escritor que su rival, sirviéndose de la misma técnica imitativa y satírica que la había utilizado en la Primera parte con los acontecimientos militares de la Vida y trabajos de Gerónimo de Passamonte. La imitación de Cervantes no es de carácter admirativo, sino satírico o meliorativo.

$\mathrm{Su}$ imitación había sido puntualizada ya en los preliminares de la versión francesa del Quijote de Avellaneda en 1704 y en una versión española en 1732. Sin embargo, estas sugerencias no tuvieron eco en la historia literaria. Durante el Romanticismo don Quijote de Cervantes fue entendido como prototipo del héroe idealista y fracasado; y el concepto romántico de la originalidad creativa no reveló la naturaleza imitativa de la novela de Cervantes. La Segunda parte del Quijote ha sido siempre vista como obra autónoma o en consonancia con la Primera parte de la novela de Cervantes, mientras que su dependencia con la novela de Avellaneda ha sido percibida sólo a partir del siglo XX.

Cervantes quiso mostrarle a su rival en todo momento su superioridad literaria sea burlándose de los episodios del texto de Avellaneda sea tratando de superarlos con episodios más ingeniosos. Además Cervantes corrigió las características personales que Avellaneda había otorgado a don Quijote y Sancho y a otros personajes de la Primera parte, destacando de este modo que los verdaderos personajes nada tienen que ver con los que aparecen en el Quijote apócrifo.

La respuesta al Quijote apócrifo empieza ya al inicio del primer capítulo de la Segunda parte. Cervantes inicia su Ingenioso caballero don Quijote de la Mancha: «Cuenta Cide Hamete Benengeli, en la segunda parte desta historia y tercera salida de don Quijote» (Cervantes, II, 1: 681). Cervantes, como Avellaneda («entre ciertos anales de historias halló escrita en arábigo la tercera salida que hizo del lugar del Argamasilla», Avellaneda, I: 208) menciona la tercera salida de don Quijote; Cervantes además habla de la segunda parte de su historia para desautorizar la continuación de Avellaneda que empieza con la quinta parte de las aventuras de don Quijote (Quinta parte del Ingenioso hidalgo don Quijote de la Mancha y de su andantesca caballería), aunque Cervantes mismo había establecido en su Primera parte la división en cuatro partes.

De Ginés de Pasamonte se habla primero en los capítulos III y IV donde se comenta el robo y el hallazgo del asno de Sancho. El bachiller Sansón Carrasco dice 
que muchos lectores de la Primera parte critican la falta de memoria del autor porque se le olvidó contar quién le había robado el rucio al escudero Sancho. Este luego explica que, tras la aventura de los galeotes, le robaron el rucio y unos días después «conocí mi asno, y que venía sobre él en hábito de gitano aquel Ginés de Pasamonte, aquel embustero y grandísimo maleador que quitamos mi señor y yo de la cadena» (Cervantes, II, 4: 716).

En los capítulos XXV al XXVII se cuenta el episodio del retablo de la libertad de Melisendra donde Ginés de Pasamonte reaparece disfrazado en el titiritero (titerero) y adivino maese (mase) Pedro, personaje que representa una auténtica revelación sobre la identidad de Avellaneda. Este personaje dirige una representación basada en el Entremés de Melisendra de Lope de Vega, que es interrumpida por don Quijote. En el texto de Avellaneda igualmente fue interrumpida la representación de El testimonio vengado, obra también de Lope de Vega. En el episodio Cervantes hace varias alusiones al texto de Avellaneda y a la autobiografía de Passamonte, de modo que al final el lector puede concluir que Ginés de Pasamonte es la representación literaria de Gerónimo de Passamonte.

Entre los capítulos XXX y LVII don Quijote se aloja en el palacio de los duques; en estos episodios se pueden enumerar numerosas referencias al Quijote apócrifo y se supone una clara réplica de los episodios ocurridos a don Quijote de Avellaneda entre los nobles.

En el capítulo LIX Cervantes cambia su estrategia, porque si hasta ahora ha tratado el texto de Avellaneda de forma encubierta sin referencias directas, ahora lo menciona por primera vez explícitamente. Se considera que antes de redactar el capítulo LIX Cervantes se dio cuenta de la publicación del Quijote apócrifo. Por eso en este capítulo por primera vez se hace mención clara del texto de Avellaneda:

Para qué quiere vuestra merced, [...] que leamos estos disparates, si el que hubiere leído la Primera parte de la historia de don Quijote de la Mancha no es posible que pueda tener gusto en leer esta segunda? -Con todo eso - [...], será bien leerla, pues no hay libro tan malo, que no tenga cosa buena (Cervantes, II, 59: 1213).

Al mismo tiempo aparece el personaje que se llama don Jerónimo. Este personaje luego entrega a don Quijote el libro apócrifo, teniéndolo por el verdadero. De esta forma, Cervantes logra que su don Quijote resulte el auténtico por la propia representación literaria de don Quijote de Avellaneda.

Hasta el final de la Segunda parte Cervantes sigue aludiendo al texto de Avellaneda. Por ejemplo, al final se impide que algún otro autor resucite a don Quijote «y hiciese inacabables historias de sus hazañas» (Cervantes, II, 74: 1335). Y se añade a continuación: «Este fin tuvo el ingenioso hidalgo de la Mancha, cuyo lugar no quiso poner Cide Hamete puntualmente, por dejar que todas las villas y lugares de la Mancha contendiesen entre sí por ahijársele y tenérsele por suyo, como contendieron las siete ciudades de Grecia por Homero» (Cervantes, II, 74: 1335). Cervantes no precisa el pueblo de don Quijote y niega que este pueblo sea 
Argamasilla, como dice Avellaneda ya en el primer capítulo, desmitiendo una vez más a su rival.

Cervantes escribió el Prólogo a la Segunda parte de su Quijote una vez que ya conocía la publicación del Quijote apócrifo. En todo el prólogo Cervantes parece preocuparse sólo a responder a su rival. Ya al principio pone en duda el origen del autor apócrifo. Y se siente profundamente dolido porque Avellaneda le ha calificado de viejo y manco, «como si hubiera sido en mi mano haber detenido el tiempo, que no pasase por mí, si mi manquedad hubiera nacido en laguna taberna, sino en en la más alta ocasión que vieron los siglos pasados, los presentes, ni esperan ver los venideros» (Cervantes, II, Prólogo: 673). A continuación Cervantes se refiere a la envidia de Lope de Vega cuyo comportamiento libertino califica con ironía.

¿Cómo recibió Passamonte la respuesta de Cervantes? No lo sabemos porque Avellaneda o Passamonte no continuó la disputa literaria, se quedó mudo, sin respuesta. Cervantes seguramente sabía quién era el autor apócrifo y, como la crítica reciente ha probado con numerosos ejemplos, sabía también que su rival literario no era sólo Lope de Vega sino también Jerónimo de Passamonte. ¡Y para bien de todos! Alfonso Martínez Jiménez opina que:

El hecho de que el mismo Cervantes identificara a Pasamonte con Avellaneda apenas deja lugar a dudas sobre la identidad del autor del Quijote apócrifo, y el cotejo de esta obra con la autobiografía de Pasamonte, así como los indicios que Avellaneda dejó en su texto sobre su lugar de origen y su verdadera identidad, corrobaron que Cervantes no estaba equivocado» (Martín Jiménez, 2006: 407).

Esta revelación no disminuye en ningún aspecto la genialidad de la inmortal obra cervantina ni su importancia para la literatura occidental de modo que seguirá válida la afirmación de Dostoyevski:

No hay en todo el mundo una obra literaria más profunda ni más poderosa. Hasta el momento, es esta la más alta expresión del pensamiento humano [...]. Y si el mundo fuera a terminar y se le preguntara a alguien en algún lugar: «¿Entendieron ustedes su vida sobre la tierra, y qué conclusiones han sacado?», el hombre podría contestarle silenciosamente entregando en mano a Don Quijote (Gilman, 1989: 76).

\footnotetext{
${ }^{11}$ Avellaneda se basó en los poemas finales de la primera parte del Quijote, compuestos por los académicos de la Argamasilla, aunque Cervantes nunca lo había afirmado explícitamente.
} 


\section{Bibliografía}

Avellaneda, Alonso Fernández de (2000): El ingenioso hidalgo don Quijote de la Mancha. Madrid: Biblioteca Nueva.

Cervantes, Miguel de (2004): Don Quijote de la Mancha. Barcelona: Galaxia Gutenberg, Círculo de Lectores.

Gilman, Stephen (1989): Cervantes y Avellaneda. Estudio de una imitación. México: El Colegio de México.

Gómez CANSECo, Luis (2000): Introducción al Ingenioso hidalgo don Quijote de la Mancha de Alonso Fernández de Avellaneda. Madrid: Biblioteca Nueva.

RiLeY, Edward C. (2004): Introducción al "Quijote”. Barcelona: Crítica.

RiQuer De, Martín (1988): Cervantes, Passamonte y Avellaneda. Barcelona: Sirmio. Marín,

Nicolás (1988) «La piedra y la mano en el prólogo del Quijote apócrifo». Estudios literarios sobre el Siglo de Oro. Granada: Universidad de Granada, 279-313.

Martín JimÉnez, Alfonso (2001): El Quijote de Cervantes y el Quijote de Pasamonte. Alcalá de Henares: Centro de Estudios Cervantinos.

-, (2005): Cervantes y Pasamonte. La réplica cervantina al "Quijote” de Avellaneda. Madrid: Biblioteca Nueva.

-, (2006): «De Avellaneda y Avellanedas». Edad de Oro, XXV. Madrid: Ediciones de la Universidad Autónoma de Madrid.

Rico, Francisco (1993): El sueño del humanismo. De Petrarca a Erasmo. Madrid: Alianza Universidad.

\section{Povzetek \\ DON KIHOT Z DVEMA OBRAZOMA - CERVANTES PROTI AVELLANEDI}

Leta 1605 je bil v Madridu objavljen Veleumni plemič don Kihot iz Manče, ki ga je podpisal Miguel de Cervantes Saavedra. Leta 1614 pa je bil v Tarragoni objavljen Segundo tomo del ingenioso hidalgo don Quijote de la Mancha (Drugi del veleumnega plemiča don Kihota iz Manče), ki ga je napisal in podpisal Alonso Fernández de Avellaneda. Objava apokrifnega Don Kihota je zastavila eno največjih ugank španske klasične književnosti - kdo v resnici je Alonso Fernández de Avellaneda? Kljub štiristoletnim raziskovalnim naporom cervantistov po vsem svetu je skrivnostna identiteta apokrifnega avtorja ostala do danes nerazkrita.

V začetku dvajsetega stoletja so v Neaplju našli rokopis avtorja Gerónima de Passamonteja z naslovom Vida y trabajos de Gerónimo de Passamonte (Življenje in dela Gerónima de Passamonteja, 1593), ki ga do poznih osemdesetih let kritika ni primerno obravnavala. Passamonte je po najnovejših raziskavah prav Avellaneda in zdi se, da je že na prvi del Cervantesovega Don Kihota vplival tudi omenjeni rokopis.

Cervantes je leta 1615 objavil drugi del svojega viteškega romana. Večina študij, ki se loteva te teme, se ukvarja z osebo skrivnostnega avtorja in z zgodovinskim okoljem; veliko manj pa se jih loteva podobnosti in razlik med Cervantesovim in Avellanedovim delom. Pričujoči članek skuša na posameznih primerih osvetliti določene povezave med omenjenimi štirimi besedili. 